NASA Technical Memorandum 106959

AIAA-95-2613

\title{
Grid Resolution and Turbulent Inflow Boundary Condition Recommendations for NPARC Calculations
}

Nicholas J. Georgiadis and Julianne C. Dudek

Lewis Research Center

Cleveland, Ohio

and

Thomas P. Tierney

Massachusetts Institute of Technology

Cambridge, Massachusetts

Prepared for the

31st Joint Propulsion Conference and Exhibit cosponsored by AIAA, ASME, SAE, and ASEE San Diego, California, July 10-12, 1995
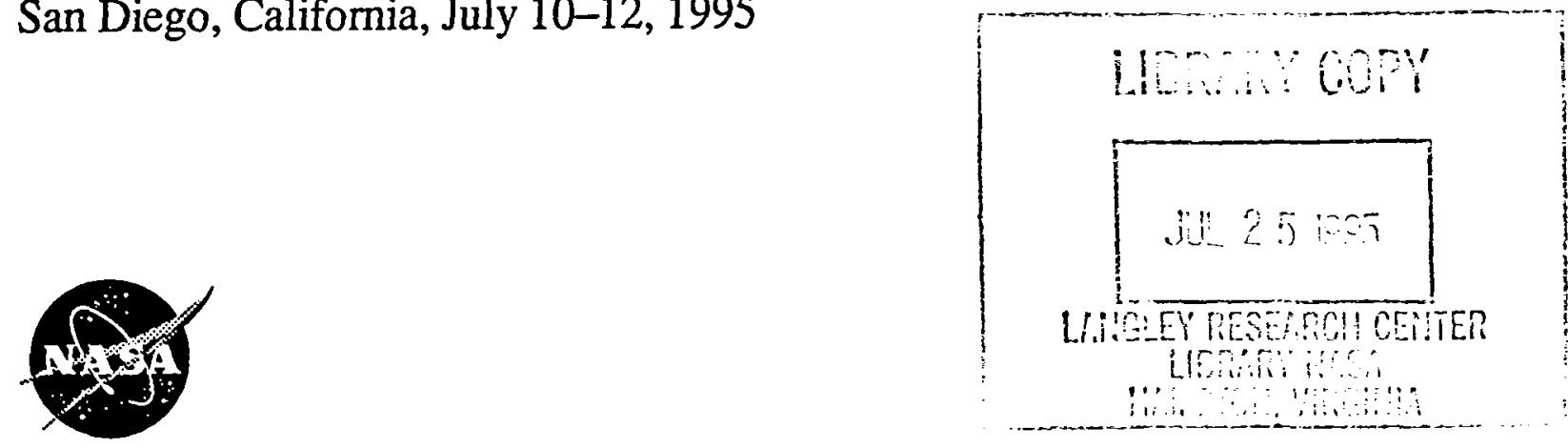

National Aeronautics and Space Administration 


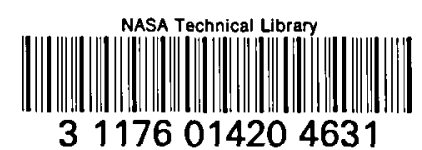

\title{
GRID RESOLUTION AND TURBULENT INFLOW BOUNDARY CONDITION RECOMMENDATIONS FOR NPARC CALCULATIONS
}

\author{
Nicholas J. Georgiadis and Julianne C. Dudek \\ National Aeronautics and Space Administration \\ Lewis Research Center \\ Cleveland, Ohio \\ and \\ Thomas P. Tierney \\ Massachusetts Institute of Technology \\ Cambridge, Massachusetts
}

\begin{abstract}
$\underline{\text { Abstract }}$
The effects of grid resolution and specification of turbulent inflow boundary conditions were examined using the NPARC code with the Baldwin-Lomax and Chien $k-\varepsilon$ turbulence models. Three benchmark turbulent test cases were calculated: two were wall bounded flows and the third was a compressible mixing layer. The wall bounded flows were essentially insensitive to axial grid density; however, the location of the first point off the wall had a substantial effect on flow solutions. It was determined that the first point off the wall must be in the laminar sublayer $(y+\leq 5)$ for the entire boundary layer. For the compressible mixing layer case, the axial grid density affected the capturing of oblique shock waves in the mixing region, but the overall mixing rate was not strongly dependent on grid resolution. In specifying the inflow turbulent boundary conditions, it was very important to match the boundary layer and momentum thicknesses of the two flows entering the mixing region; calculations obtained with smaller or no boundary layers resulted in substantially reduced mixing. The solutions were relatively insensitive to freestream turbulence level.

\section{Nomenclature}

b mixing layer thickness

$\mathrm{C}_{\mathrm{f}} \quad$ skin friction coefficient

$k$ turbulent kinetic energy

$\mathrm{l}_{\text {ref }}$ reference length for NPARC calculations

$P_{S} \quad$ static pressure

$\mathrm{P}_{\mathrm{T}} \quad$ total pressure

$\mathrm{Re}_{\mathrm{x}} \quad$ Reynolds number based on axial position

$\operatorname{Re}_{\theta} \quad$ Reynolds number based on momentum thickness

$\mathrm{T}_{\mathrm{s}} \quad$ static temperature

$\mathrm{T}_{\mathrm{T}}$ total temperature

U velocity
\end{abstract}

This paper is declared a work of the U.S. Government and is not subject to copyright protection in the United States.
$\mathrm{U}_{\mathrm{cl}} \quad$ local centerline velocity for the adverse pressure gradient diffuser case

$\mathrm{U}_{\mathrm{fs}} \quad$ freestream velocity for the flat plate case

$\mathrm{U}_{1} \quad$ velocity of high speed stream for the mixing layer case

$\mathrm{U}_{2} \quad$ velocity of low speed stream for the mixing layer case

$u^{*} \quad$ shear velocity

$\mathrm{x}, \mathrm{y} \quad$ Cartesian coordinates

$y+\quad$ distance from wall normalized by shear length scale

$\delta \quad$ boundary layer thickness

$\delta^{*} \quad$ displacement thickness

$\varepsilon \quad$ rate of turbulent kinetic energy dissipation

$\mu \quad$ dynamic viscosity

$\mu_{\mathrm{t}} \quad$ turbulent viscosity

$v \quad$ kinematic viscosity

$\theta$ momentum thickness

\section{Introduction}

The National PARC (NPARC) Alliance was established as a partnership between NASA Lewis Research Center and USAF Arnold Engineering Development Center to provide the United States aerospace community with a reliable Navier-Stokes solver for propulsion flow simulations.1 As part of the NPARC Alliance's efforts, the two equation turbulence model in the code was modified to incorporate the low Reynolds number $k-\varepsilon$ model of Chien. ${ }^{2}$ The implementation of this model in NPARC enabled more accurate calculations of complex propulsion flows than was possible with the previous $k-\varepsilon$ model or with any of the available algebraic models. ${ }^{3}$

Although the implementation of the Chien k- $\varepsilon$ model in NPARC has been completed and has been available for use, guidelines for sufficient grid resolution, especially 
near solid walls, have not been documented. In addition, the effects of specifying different turbulent inflow boundary conditions have not been thoroughly examined. Since determining appropriate values for $\mathrm{k}$ and $\varepsilon$ at an inflow is often difficult, extrapolation of these quantities has been the default inflow boundary condition in NPARC for use with the Chien model. Reference 3 , however, showed that flow calculations involving mixing layers are dependent on inflow boundary conditions.

In this study, the effects of grid resolution and specification of turbulent boundary conditions were examined for three benchmark test cases in order to establish guidelines for calculation of more complex propulsion flows with NPARC. Two wall bounded flows were examined: an incompressible flat plate boundary layer and a subsonic diffuser flow with an adverse pressure gradient. The third test case, a compressible turbulent shear layer, was investigated to determine the effects of both grid resolution and inflow boundary conditions on the calculation of mixing of two streams. The Chien k- $\varepsilon$ model was used to calculate all three flows. The BaldwinLomax algebraic turbulence model 4 was also used to calculate the two wall bounded flows, but since BaldwinLomax is not intended for free shear layers, it was not applied to the mixing layer case.

\section{Grid Generation and NPARC Inputs}

Grids for the three test cases considered were generated using a version of the INGRID interactive grid generation program 5 which has the capability for grid visualization. Grids were packed to solid walls using hyperbolic tangent stretching. The total number of grid points used and the grid packing is described in the following sections for each test case. NPARC-Version 2.0 was used for all of the calculations. Details of the NPARC 2.0 flow solver may be found in Ref. 1 and details of the Chien $k-\varepsilon$ and Baldwin-Lomax turbulence models may be found in Refs. 2 to 4. Default values for the NPARC inputs were used except for the inputs mentioned specifically in the following discussion of the three test cases. The modified Jameson-style artificial viscosity (IFILTR $=2$ ) and Jameson-style spectral radius term (ISPECT $=1$ ) were used for all of the calculations. The 2 nd order artificial viscosity coefficient (DIS2) was set to 0.10 , although increasing this coefficient to 0.25 (the default value) or decreasing it to 0.00 had very little effect on the flow solutions.

\section{Discussion of Flow Cases}

\section{(1) Flat Plate Boundary Layer}

Flow over a flat plate was investigated to determine the effects of (1) grid spacing at the leading edge of the plate, (2) total number of axial grid points required to adequately resolve the boundary layer, and (3) the vertical grid packing required near the no-slip boundary. This flow case was established with NPARC by specifying the total pressure at the inflow and static pressure at the outflow corresponding to Mach 0.2 flow at atmospheric conditions. A fixed inflow profile was not used for these calculations. Instead, the flow reached the leading edge of the plate at grid point 15 in the horizontal direction $(x=0.0 \mathrm{~m})$ where the boundary layer began and then continued downstream over the no-slip surface for a distance of $5.0 \mathrm{~m}$. A schematic of the flat plate test case is shown in Fig. 1. Reference 3 showed that extrapolation of the turbulent quantities $\mathrm{k}$ and $\varepsilon$ was an appropriate boundary condition for wallboundary layer calculations and as a result, was used for the calculations obtained here.

The first set of calculations investigated the effect of axial grid spacing near the leading edge. Two different grids were used, both having 111 points in the axial direction ( 96 points from the leading edge to the outflow) and 81 points in the vertical direction. In the first grid, the points were axially clustered at the leading edge such that the minimum spacing was $0.24 \mathrm{~mm}$ and increased with downstream distance along the plate. The second grid had uniform axial grid spacing. Both grids were clustered vertically at the wall such that the average value of $y+a t$ the first point off the wall was 2 ; where $y+$ is defined by $\mathrm{y}+=\mathrm{yu} * / v$ and assuming a skin friction coefficient corresponding to 0.003 and the freestream flow conditions.

Skin friction profiles over the flat plate obtained from NPARC calculations using different axial grid spacings are compared with experimental data of Wieghardt 6 for both the Baldwin-Lomax and Chien k- $\varepsilon$ turbulence models as shown in Fig. 2. There is significant discrepancy between the two $k-\varepsilon$ solutions: namely, the solution obtained with the evenly packed grid has a nearly flat skin friction profile. The Baldwin-Lomax solutions showed some discrepancy upstream, but the magnitude of the difference was not as large as for the $k-\varepsilon$ solutions.

The second grid parameter examined for the flat plate was the number of axial grid points. A new grid was generated that was packed to the no-slip wall with the first point off the wall at $y+=2$ and packed to the leading edge with the minimum spacing set to $0.24 \mathrm{~mm}$. The number of grid points from the leading edge to outflow, however, was doubled from 96 to 192 . Figure 3 compares the skin friction profiles obtained with the new grid to the more coarse grid (but packed to the leading edge) solution shown in Fig. 2. These skin friction results show that the effect of grid density was less significant than when the grid was packed to the leading edge, particularly for the Chien k- $\varepsilon$ model.

The effects of grid resolution in the direction normal to the plate was examined next. Reference 7 showed that 
the number of grid points normal to a no-slip boundary was not as important as the placement of the first point off the wall. As a result, the location of the first point off the wall was varied for grids having 111 points in the axial direction by 81 points in the vertical direction. Five grids were constructed that had the first point off the wall located at an average $y+$ of $1,2,5,10$, and 30 . The grid was packed to the leading edge in the axial direction, as described previously.

A comparison of the flow solutions obtained from these grids is provided in Figs. 4 to 8 for the Chien $k-\varepsilon$ solutions and in Figs. 9 to 13 for the Baldwin-Lomax solutions. Examining the $k-\varepsilon$ solutions shows that none of the NPARC calculations match the experimental data exactly, but the solutions obtained with the $y+=1$ and $y+=2$ grids produce the same solution and, as the first point is moved further away from the no-slip surface, the skin friction drops. The boundary layer, displacement, and momentum thicknesses obtained from the NPARC calculations are compared to correlations of Schlichting (Ref. 8) in Fig. 5. These three measures of boundary layer growth indicate that only the $y+=1, y+=2$, and $y+=5$ solutions produce adequate boundary layer predictions. As the first point is placed further away from the wall (outside the laminar sublayer), the error increases. The velocity profiles at a position corresponding to $\mathrm{Re}_{\mathrm{x}}=10,000,000$ in Fig. 6 also show that, as the average $y+o f$ the first point is increased, the discrepancy increases.

In the Chien model, the damping terms in the differential equation for $\varepsilon$ and the algebraic expression for turbulent viscosity $\mu_{4}$ require the calculation of $y+$, which is a function of the wall shear stress. If the first point off the wall is not in the laminar sublayer, the velocity gradient used to calculate the wall shear stress will be inaccurate (since the velocity gradient is constant only in the laminar sublayer) and therefore the damping functions will be in error. The profiles of $k, \varepsilon$, and $\mu_{\mathrm{s}}$ at $\operatorname{Re}_{\mathrm{x}}=10,000,000$ in Fig. 7 show significantly different behavior among the solutions obtained with the different grids. Avva, Smith, and Singhal $^{9}$ have also shown that low Reynolds number $k-\varepsilon$ models are very sensitive to the placement of the first point away from solid boundaries. Although $y+=5$ is usually considered to be within the laminar sublayer, the flow considered here with an average $y+=5$ had some points near the leading edge of the plate at a $y+>5$ (because the skin friction is greatest at the leading edge). The grids with average $y+$ values at the first point off the wall of 1 and 2 did not have any local $y+$ values greater than 5 , even near the leading edge. Figure 8 shows the turbulent viscosity at the first point off the wall. The $y+=10$ and $y+=30$ cases had turbulent viscosities that exceeded the laminar viscosity along the entire plate, which resulted in the substantially different turbulent quantities in Fig. 7 and the incorrect boundary layer characteristics of Figs. 5 and 6.

The placement of the first point off the wall had a significant effect on the Baldwin-Lomax solutions as well. Unlike the Chien $k-\varepsilon$ calculations, however, a grid independent solution was not obtained, even for the grids having $y+=1$ or 2 at the first point off the wall. The skin friction comparison of Fig. 9 shows that as the normal grid spacing is increased, the skin friction first increases $(y+=1$ to $y+=2)$ and then decreases as the first point is moved outside the laminar sublayer. The boundary layer quantities shown in Figs. 10 and 11 demonstrate a trend opposite that observed for the Chien k- $\varepsilon$ results: as the first point is moved well outside the laminar sublayer, the flow appears to be much less turbulent than was the case with the $k-\varepsilon$ solutions. Figure 12 shows that the peak turbulent viscosity is much lower for the $y+=30$ grid than for the more tightly packed grids using Baldwin-Lomax, while the trend was the opposite for the $k-\varepsilon$ calculations. The turbulent viscosities at the first point off the wall (Fig. 13) for the $y+=30$ grid solution are much lower than those obtained for the $k-\varepsilon$ solution with $y+=30$ grid.

\section{(2) Adverse Pressure Gradient Diffuser Flow}

In order to investigate an adverse pressure gradient wall-bounded flow, the Fraser (flow A) case from the AFOSR-IFP-Stanford Conference (1968)10,11 was calculated with NPARC. In the experiment, a length of $152 \mathrm{~mm}$ diameter straight pipe preceded a $5^{\circ}$ half angle conical diffuser. The core flow velocity at the diffuser entrance was approximately $52 \mathrm{~m} / \mathrm{s}$ (Mach 0.15 ). Measurements of velocity profiles and skin friction were made at several locations in the diffuser. The first measurement station, corresponding to $x=117 \mathrm{~mm}$, is slightly upstream of the beginning of the diffusing section; the last measurement station, corresponding to $x=642 \mathrm{~mm}$, is just upstream of the exit plane of the diffusing section. A schematic of the diffuser flow is shown in Fig. 14.

Two different grids were used for these axisymmetric calculations. The first had 113 points in the axial direction and 71 in the radial direction, while the second had 221 points in the axial direction and 71 in the radial direction. Based on the results from the flat plate investigation, the grid was packed to the leading edge (pipe entrance) and to the no-slip surface such that the $y+$ of the first point off the wall was approximately 1 (based on the core flow velocity at the first measurement station and an assumed skin friction coefficient of 0.003 ). The inflow was specified as a free boundary and placed $610 \mathrm{~mm}$ upstream of the first measurement station in an attempt to match the experimentally measured momentum and displacement 
thicknesses at the beginning of the diffusing section. The turbulence quantities were extrapolated at the inflow for the $k-\varepsilon$ calculations.

The outflow location and outflow boundary condition were varied to determine their effects on the flow calculations using the Chien $k-\varepsilon$ turbulence model and the coarse grid (113 points by 71 points). Three outflow locations were examined: (1) the last measurement station (the true diffuser exit plane), (2) $150 \mathrm{~mm}$ downstream of this last station, and (3) $370 \mathrm{~mm}$ downstream of the last station. The latter two outflows were examined because the flow solution obtained with the exit at the last measurement station did not conserve mass between the outflow grid line and the grid line just upstream of the outflow. This was believed to be due to the grid being at a $5^{\circ}$ angle near the diffuser wall. The two cases with the extended grid did conserve mass and produced essentially the same solution. The free boundary (type 0 ) and mass flux boundary (type 93) also provided the same flow solution. After this grid and boundary condition investigation with the Chien $k-\varepsilon$ model was completed, solutions were obtained with the $k-\varepsilon$ model for the fine grid and with Baldwin-Lomax for the coarse and fine grids. The outflow was placed at $150 \mathrm{~mm}$ downstream of the last measurement station and the mass flux boundary condition was specified.

With the inflow placed $610 \mathrm{~mm}$ upstream of the first measurement station, the NPARC solutions obtained with the two turbulence models and two grids matched the experimental displacement and momentum thicknesses closely at the first measurement station. Also, all of the solutions match the experimental skin friction well at the first station (Fig. 15). Further downstream in the diffuser, however, the agreement with experimental data is not as good. The Baldwin-Lomax calculations indicate a separation approximately half way down the diffuser while the Chien $\mathrm{k}-\varepsilon$ calculations remained attached. There was no separation in the experiment. Velocity profiles at four locations in the diffuser are shown in Fig. 16. Although the velocity profiles also exhibit increased discrepancies with experimental data further downstream in the diffuser, the Baldwin-Lomax profiles obtained with the two grids are very similar as are the $k-\varepsilon$ profiles. The skin friction comparison, however, shows greater difference between solutions obtained with the two grids, particularly with the Baldwin-Lomax turbulence model solutions near separation. The turbulent viscosity profiles at the first and last measurement stations in Fig. 17 show little variation with grid density.

From the comparisons of the solutions to experimental data, it may be concluded that the skin friction coefficient is much more sensitive than velocity and turbulent viscosity profiles to grid density. Overall, the NPARC calculations provide only fair agreement with the experimental data for this subsonic diffuser case. The objective of this study, however, was not to determine the best turbulence model for this particular flow, but instead to determine the effects of grid resolution for two turbulence models (BaldwinLomax and Chien $\mathrm{k}-\varepsilon$ ) that are used extensively to calculate flows having characteristics similar to the benchmark cases considered here. References 12 to 14 show that these two turbulence models have difficulty in calculating adverse pressure gradient flows.

\section{(3) Compressible Turbulent Shear Layer}

The third case investigated in this study was a twodimensional supersonic mixing layer. NPARC solutions were obtained for comparison with experimental data of Goebel and Dutton.15-17 This flow (Case 2 in Refs. 15 and 16) had two streams with Mach numbers of 1.91 and 1.36, which are separated by a splitter plate upstream of the mixing section. A schematic of the mixing layer test section is shown in Fig. 18. A grid resolution study was conducted first followed by an investigation of the effects of turbulent inflow boundary conditions. As mentioned previously, the Baldwin-Lomax turbulence model is not intended for the calculation of flows where free shear layer mixing is the dominant flow characteristic, and therefore only the Chien $\mathrm{k}-\varepsilon$ model was used for these calculations.

For the grid sensitivity study, five grids were constructed that varied the number of axial grid points. Each began $200 \mathrm{~mm}$ upstream of the splitter plate trailing edge $(x=0 \mathrm{~mm})$ in order to allow sufficient development of the boundary layer matching the boundary layer and momentum thicknesses measured in the experiment at the trailing edge. The mixing sections ended $500 \mathrm{~mm}$ downstream of the trailing edge. The height of the mixing section was $48 \mathrm{~mm}$. In the vertical direction, the grids had 131 points and were packed to the no-slip surfaces of the splitter plate with an average $y+$ of 1 . In the axial (streamwise) direction, the grids were packed at the inflow of the two streams and to upstream and downstream of the splitter plate trailing edge. The five grids had the following number of grid points in the axial direction: (1) 51 upstream of the splitter plate trailing edge, 190 downstream in the mixing region, (2) 91 upstream and 96 downstream, (3) 91 upstream and 190 downstream, (4) 91 upstream and 380 downstream, (5) 91 upstream and 570 downstream. The turbulent quantities were extrapolated at the inflow for all five of these calculations. Results from grids 1 and 3 were compared to determine the effects of grid density upstream of the mixing region and grids 2 to 5 were compared to determine the effects of grid resolution in the mixing region. As will be discussed in the following section, the number of grid points in the mixing region was increased until a grid independent solution was obtained. 
All of the calculations were able to match the boundary layer and displacement thicknesses at the splitter plate trailing edge to within 10 percent of the values measured in the experiment. The mixing layer growths obtained from the NPARC calculations are compared to experimental data in Fig. 19, while velocity and turbulent viscosity profiles at two locations in the mixing region are shown in Figs. 20 and 21, respectively. The mixing layer thickness was defined at each axial station as the distance from the location where the local velocity is greater than $U_{2}$ by 10 percent of $\left(U_{1}-U_{2}\right)$ to the location where the local velocity is less than $U_{1}$ by 10 percent of $\left(U_{1}-U_{2}\right)$. The three grids having 190 or fewer grid points in the mixing region did not demonstrate the nonlinear mixing layer growth shown by the grids having 380 or 570 points. The static pressure contours for the highest density grid solution (Fig. 22) show that a series of oblique shock waves was found in the mixing region, which was also observed in the experiment. It is these oblique waves that cause the mixing layer thickness pattern observed for the solutions obtained with grids having 380 and 570 points in the mixing region.

The comparison among the solutions for the velocity profiles in Fig. 20 and turbulent viscosity profiles in Fig. 21 show very little grid sensitivity. The average mixing layer thickness also is very similar among the solutions, despite the inability of the lower density grids to capture the nonlinear mixing layer growth. It may be concluded that the differences noted among the solutions were not caused by turbulence model effects, but instead by the shock wave capturing capability of the NPARC code (the continuity, momentum, and energy equations are discretized using central differencing) with the varying grid resolution in the mixing region. Static pressure contours shown in Fig. 22 for the solution obtained with 570 points in the mixing section show the reflected shock pattern. If the objective of a calculation is to determine the overall mixing rate, either one of the two coarse grids (96 and 191 points in the mixing region) appears to be sufficient.

A second set of calculations was obtained for this case; the same grid was used for all calculations but the inflow conditions and locations were varied to determine effects on mixing. Five solutions were obtained using the grid with 91 points upstream of the splitter trailing edge and 190 downstream: (1) entire grid was used but the no-slip boundary conditions applied to the splitter walls were changed to slip-wall boundaries, (2) inflow was moved up to the trailing edge of the splitter plate with uniform inflows at the trailing edge obtained from areaaveraging the solutions from the first case, (3) inflow placed at one-half the original distance (inflow $=-100$ $\mathrm{mm}$ ) to determine if smaller boundary layers would affect the mixing process, (4) baseline case from the first set of calculations (inflow $=-200 \mathrm{~mm}$ ) used with boundary layer and momentum thicknesses nearly matching those found in the experiment, (5) inflow placed at $-200 \mathrm{~mm}$ (same as for the fourth case) but with the turbulence intensity set to 1.5 percent of the inflow velocities (approximately equal to the average intensities measured in the experiment at the splitter exit plane) and turbulent viscosity set to 500 times the laminar viscosity. This turbulent viscosity was obtained by using the height of each flow's passage at the splitter plate trailing edge to calculate the characteristic turbulent length scale.

A comparison of the mixing layer thicknesses obtained from these five calculations is provided in Fig. 23. Unlike the grid sensitivity investigation, the mixing layer thicknesses seem to be strongly dependent on the inflow conditions. Figure 23 shows that the two solutions obtained for calculations beginning $200 \mathrm{~mm}$ upstream of the trailing edge provide substantially more mixing than those produced by the three solutions obtained with smaller or no boundary layers. The effect of specifying freestream turbulence, however, does not seem to be as important as the state of the wall boundary layers (and turbulence generated by the wall boundary layers) that grow into the mixing layer. Comparisons of the velocity profiles and turbulent viscosities at $100 \mathrm{~mm}$ and $450 \mathrm{~mm}$ downstream of the splitter plate trailing edge are provided in Figs. 24 and 25 , respectively. As the thicknesses of the wall boundary layers increase, the peak turbulent viscosity in the region of highest flow gradients increases, which results in a higher mixing rate. In Fig. 25(a), it may be observed that the high freestream turbulence does not increase the turbulence in the vicinity of the highest flow gradients.

Although the effects of inflow conditions are discernible from these results, an additional mixing layer phenomenon not considered here should be investigated in the future: Reference 18 mentions that the development region of a mixing layer demonstrates an overshoot in the mixing rate which eventually approaches an asymptotic spreading rate. The $k-\varepsilon$ turbulence model does not reproduce the overshoot in initial mixing that is observed in experiment. According to Ref. 18 , this is a result of the high dissipation rate of the upstream boundary layer. The high-speed nozzle mixing flows investigated in Ref. 19 with the PARC code (predecessor to NPARC) and the Chien $k-\varepsilon$ model demonstrated substantially lower initial mixing rates relative to experimental data. This may be due to both the failure of the $k-\varepsilon$ model to provide the overshoot region of mixing and the inaccurately modeled boundary layers. The results obtained for the planar mixing layer examined in this work only determined the effects of the flow developing into the shear layer. Continued work to extend the k- $\varepsilon$ model's capability to more accurately predict the overshoot region will enable more accurate mixing layer calculations. 


\section{Conclusions}

Based upon the results of this study, several recommendations are given for constructing grids and specifying inflow conditions for turbulent flow simulations with the NPARC code. For flows with wall boundary layers and no mixing regions, axial spacing is not as important as packing of the grid to the leading edge of a solid surface, where the greatest axial flow gradients are found. Location of the first point off the wall was found to be an important consideration for grid generation. With the Chien $\mathrm{k}-\varepsilon$ model, grid independent solutions were obtained using grids with an average $y+$ of 1 or 2 at the first point off the wall. Moving the first point outside of the laminar sublayer resulted in incorrect boundary layer growth and significantly higher peak turbulence levels. A grid independent solution was not obtained with the Baldwin-Lomax turbulence model, but the grids with the first point off the wall placed at an average $y+$ of 1 or 2 provided more accurate flow calculations than the grids which were packed less tightly. As the first point was moved outside the laminar sublayer, the flow solutions appeared to be less turbulent, in contrast to the $k-\varepsilon$ results.

For the adverse pressure gradient flow, only the axial spacing was varied, and the grids were packed closely to the wall $(y+=1$ at the first point off the wall) and to the inflow in the axial direction, as a result of the flat plate investigation. After approximately doubling the number of grid points in the axial direction, very little effect on velocity profiles was noted but the skin friction in the region near separation was sensitive to axial grid density.

The compressible shear layer results indicated that axial grid resolution does not appear to have a strong effect on mixing layer predictions. The variation in mixing layer thicknesses among the solutions obtained with the grids seemed to be more the result of the shock-capturing capability of NPARC (with central-differencing used for the continuity, momentum, and energy equations) than turbulence model effects. By varying the inflow boundary conditions, it was determined that specification of freestream turbulence is not important, at least for the initial mixing region. However, matching the wall boundary layer thickness (and associated turbulence levels generated from the wall boundary layers) has a stronger effect on mixing.

\section{References}

1. NPARC Alliance at NASA Lewis Research Center and Arnold Engineering Development Center: A User's Guide to NPARC, Version 2.0. Nov. 1, 1994.
2. Chien, K-Y.: Predictions of Channel and BoundaryLayer Flows With a Low-Reynolds-Number Turbulence Model. AIAA Journal, vol. 20, no. 1, Jan. 1982, pp. 33-38.

3. Georgiadis, N.J.; Chitsomboon, T.; and Zhu, J.: Modification of the Two-Equation Turbulence Model in NPARC to a Chien Low-Reynolds Number k- $\varepsilon$ Formulation. NASA TM-106710, Sep. 1994.

4. Baldwin, B.S.; and Lomax, H.: Thin-Layer Approximation and Algebraic Model for Separated Turbulent Flows. AIAA Paper 78-257, Jan. 1978.

5. Dowell, E.W., Jr.; and McClure, M.D.: 3D INGRID: Interactive Three-Dimensional Grid Generation. AEDC-TR-87-40, 1988.

6. Wieghardt, K.; and Tillmann, W.: On the Turbulent Friction Layer for Rising Pressure. NACA TM-1314, 1951.

7. Abdol-Hamid, K.S.; Lakshamanan, B.; and Carlson, J.R.: Application of Navier-Stokes Code PAB3D With $k-\varepsilon$ Turbulence Model to Attached and Separated Flows. NASA TP-3480, Jan. 1995.

8. Schlichting, H.: Boundary-Layer Theory, Seventh Ed., McGraw-Hill, New York, 1979.

9. Avva, R.K.; Smith, C.E.; and Singhal, A.K.: Comparative Study of High and Low Reynolds Number Versions of $k-\varepsilon$ Models. AIAA Paper 90-0246, 1990.

10. Fraser, H.R.: Turbulent Boundary Layer in a Conical Diffuser.J.Hydraul. Div. Amer. Soc. Civil Eng. Proc. June 1958, pp. 1684/1-17.

11. Coles, D.E.; and Hirst, E.A., eds.: Conference on Computation of Turbulent Boundary Layers. Thermosciences Division, Stanford University, 1969.

12. De Henau, V.; Raithby, G.D.; and Thompson, B.E.: Prediction of Flows With Strong Curvature and Pressure Gradient Using the k- $\varepsilon$ Turbulence Model. J. Fluid Eng. Trans. ASME, vol. 112, March 1990, pp. 40-47.

13. Rodi, W.; and Scheuerer, G.: Scrutinizing the k- $\varepsilon$ Turbulence Model Under Adverse Pressure Gradient Conditions. J. Fluid Eng. Trans. ASME, vol. 108, June 1986, pp. 174-179.

14. Menter, F.R.: Improved Two-Equation k- $\omega$ Turbulence Models for Aerodynamic Flows. NASA TM-103975, October 1992.

15. Goebel, S.G.; and Dutton, J.C.: An Experimental Study of Compressible Turbulent Mixing Layers. AIAA Journal, vol. 29, no. 4, April 1991, pp. 538-546. 
16. Goebel, S.G.: An Experimental Investigation of Compressible Turbulent Mixing Layers. $\mathrm{Ph}$. D. Thesis, Illinois Univ. at Urbana-Champaign, 1990.

17. Goebel, S.G.; and Dutton, J.C.: Velocity Measurements of Compressible Turbulent Mixing Layers. AIAA Paper 90-0709, 1990.
18. Birch, S.F.: The Effect of Initial Conditions on High Reynolds Number Jets. AIAA Paper 83-1681, 1983.

19. Georgiadis, N.J.; and Yoder, D.A.: Use of NavierStokes Methods for the Calculation of High-Speed Nozzle Flow Fields. ALAA Paper 94-3212, 1994. 


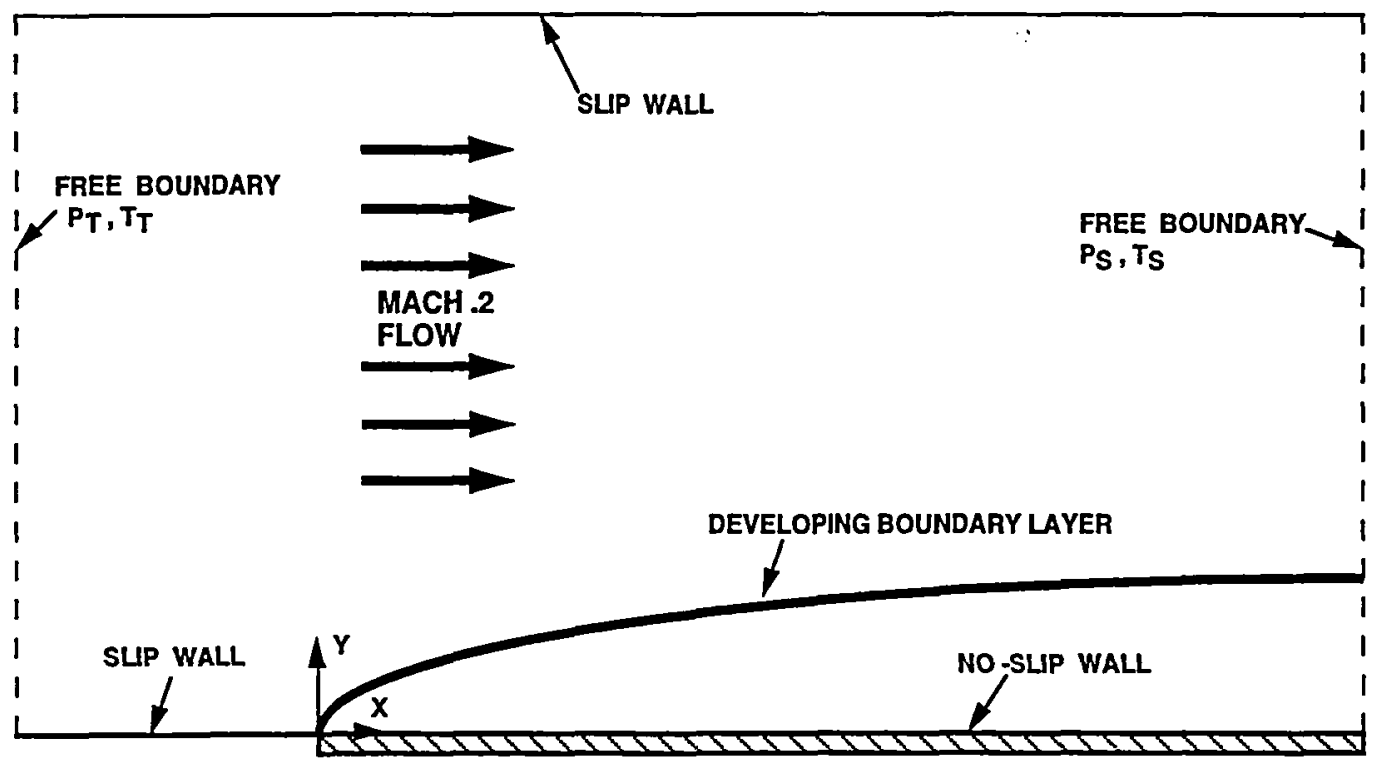

Fig. 1. Schematic of flat plate test case.

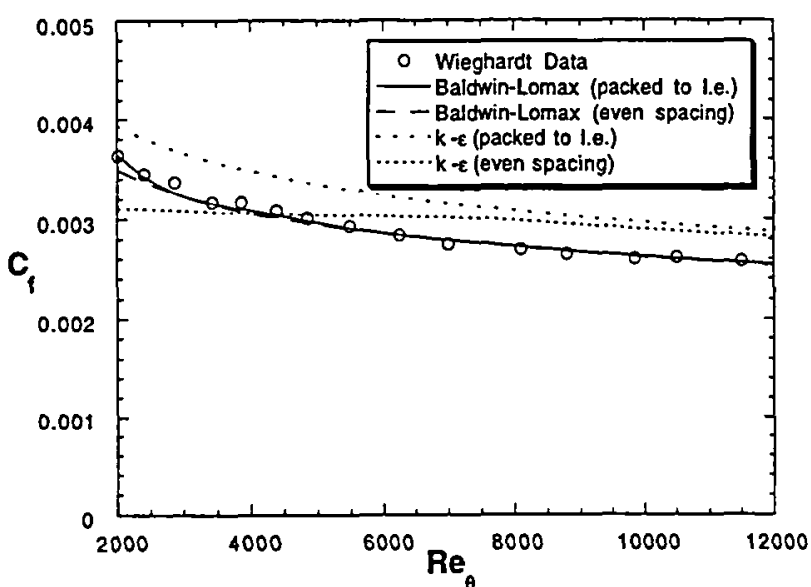

Fig. 2. Skin friction coefficient comparison for axial grid packing variations.

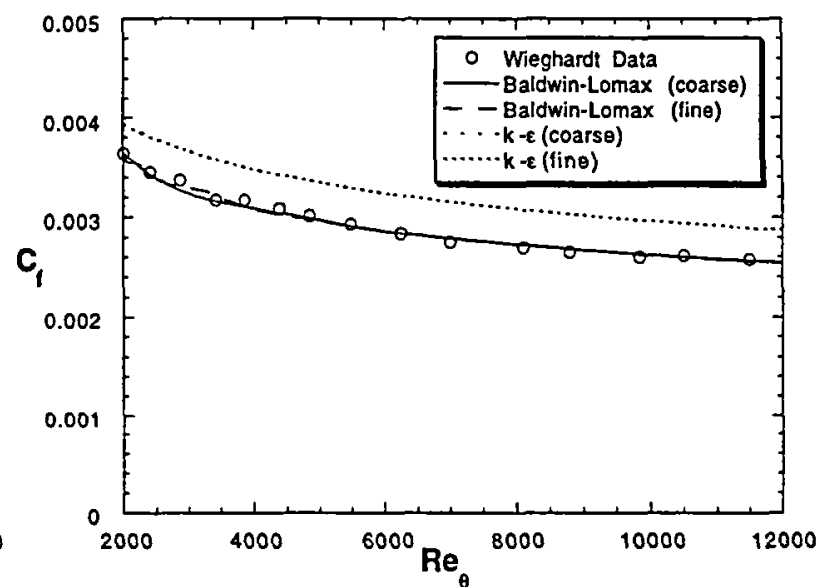

Fig. 3. Skin friction coefficient comparison for axial grid density variations.

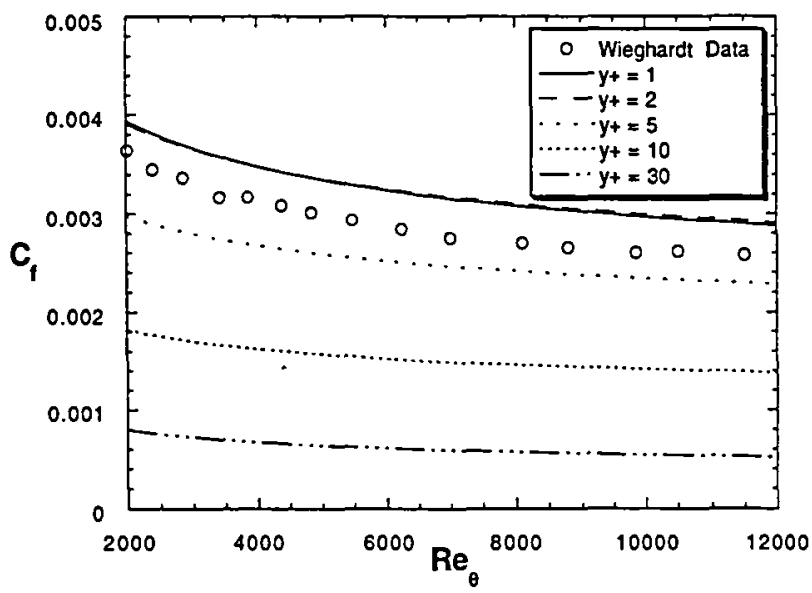

Fig. 4. Skin friction coefficient comparison for $k-\varepsilon$ solutions. 


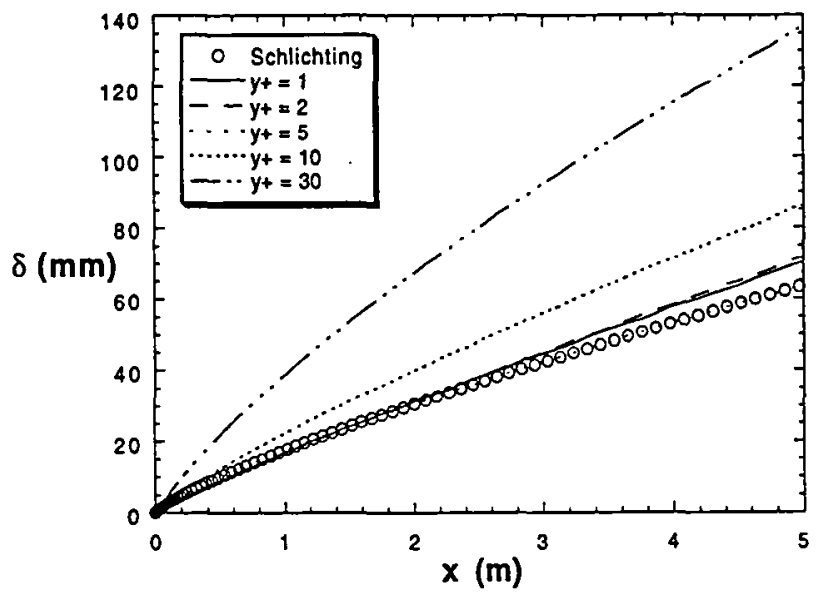

(a) Boundary layer thickness.

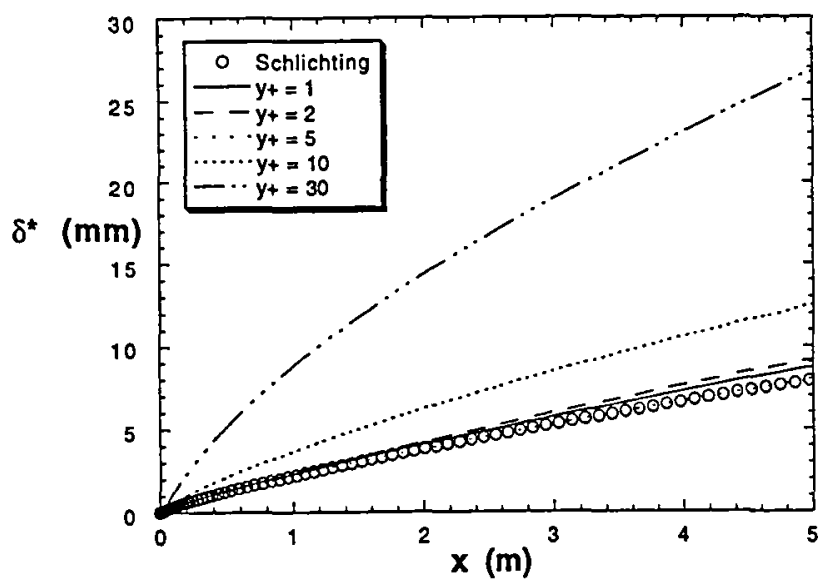

(b) Displacement thickness.

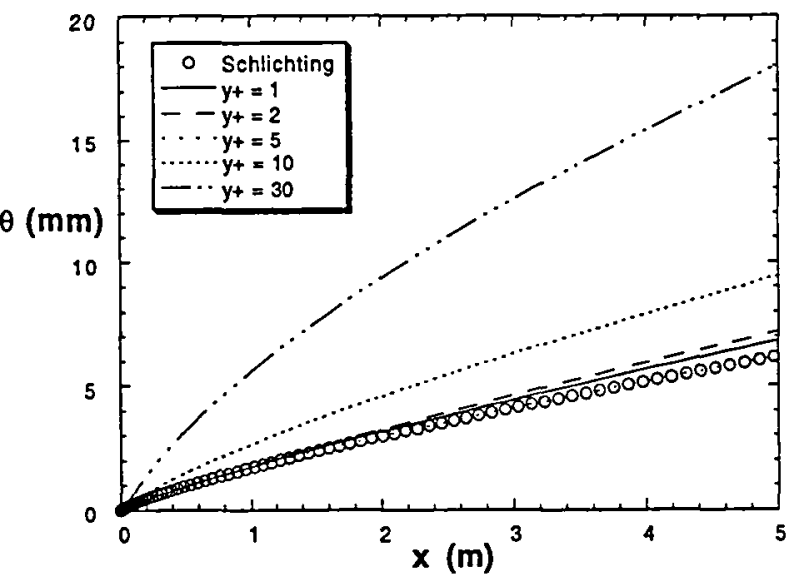

(c) Momentum thickness.

Fig. 5. Boundary layer quantities for the $k-\varepsilon$ solutions.

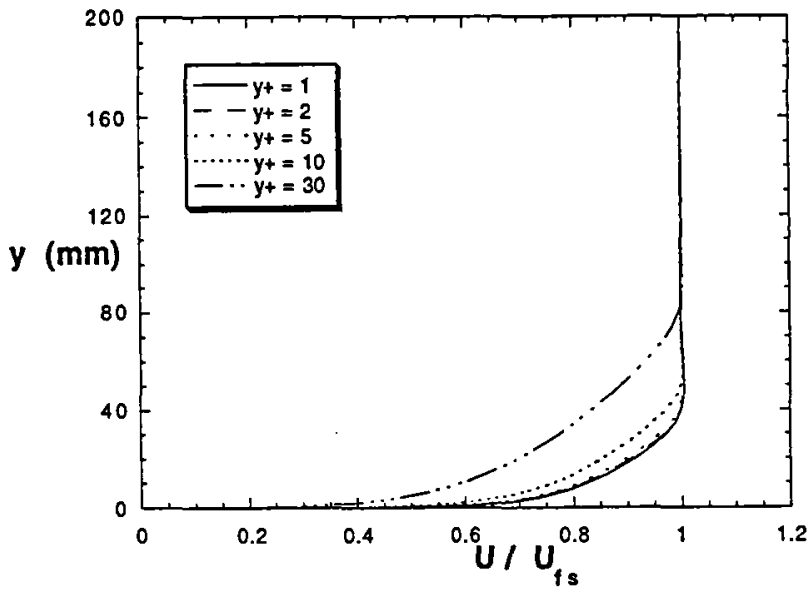

Fig. 6. Velocity profiles at $\operatorname{Re}_{x}=10,000,000$ for $k-\varepsilon$ solutions. 


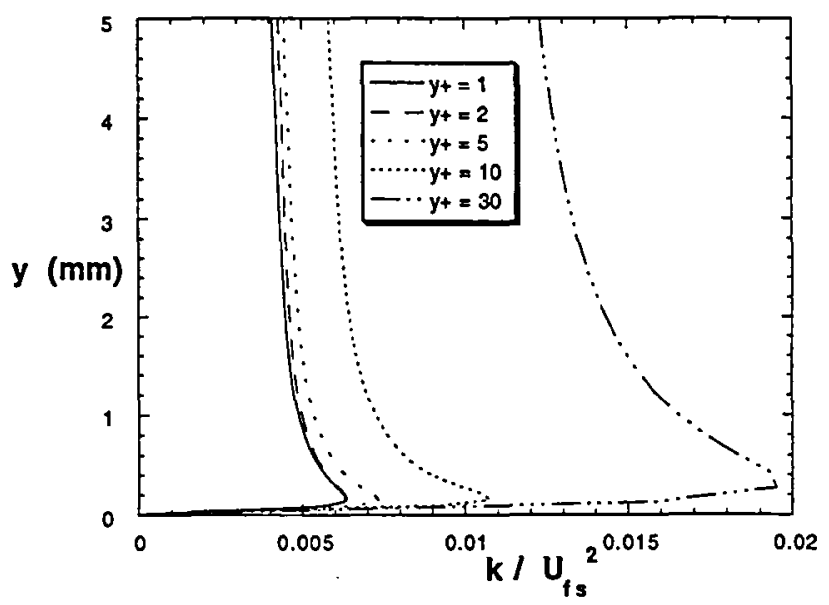

(a) Turbulent kinetic energy.

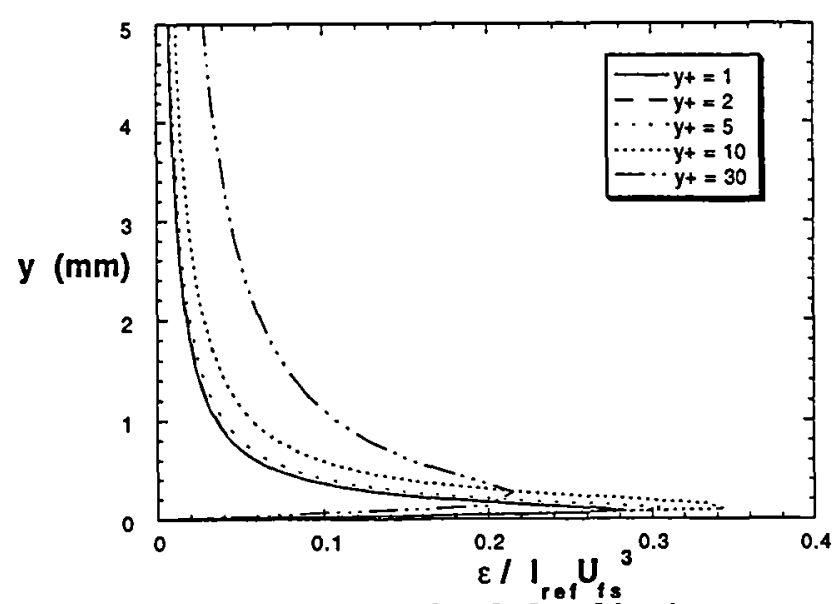

(b) Dissipation of turbulent kinetic energy.

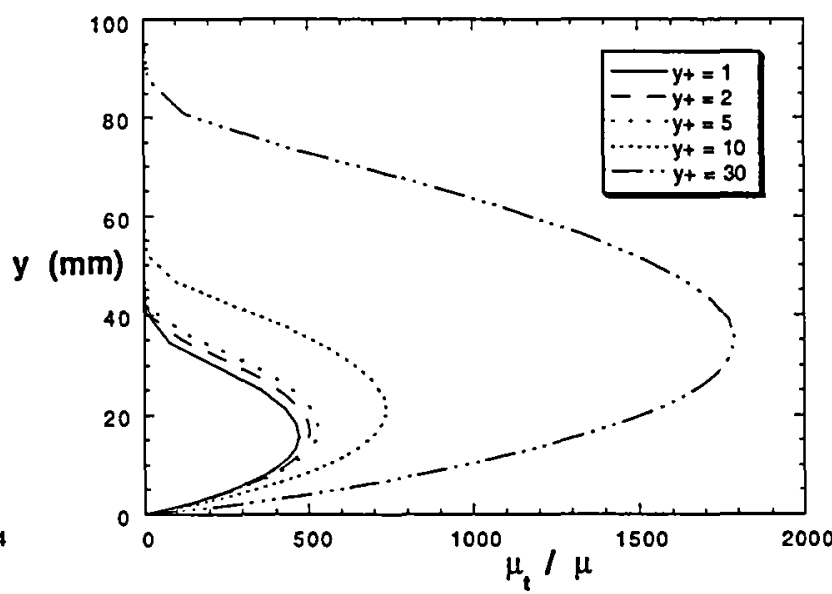

(c) Turbulent viscosity.

Fig. 7. Comparison of turbulent quantities for the $k-\varepsilon$ solutions.

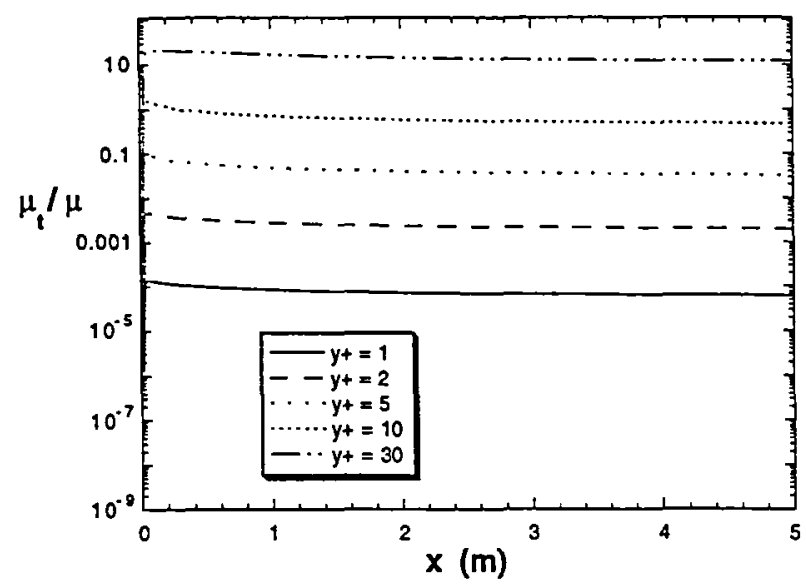

Fig. 8. Turbulent viscosity at the first point off the wall. 


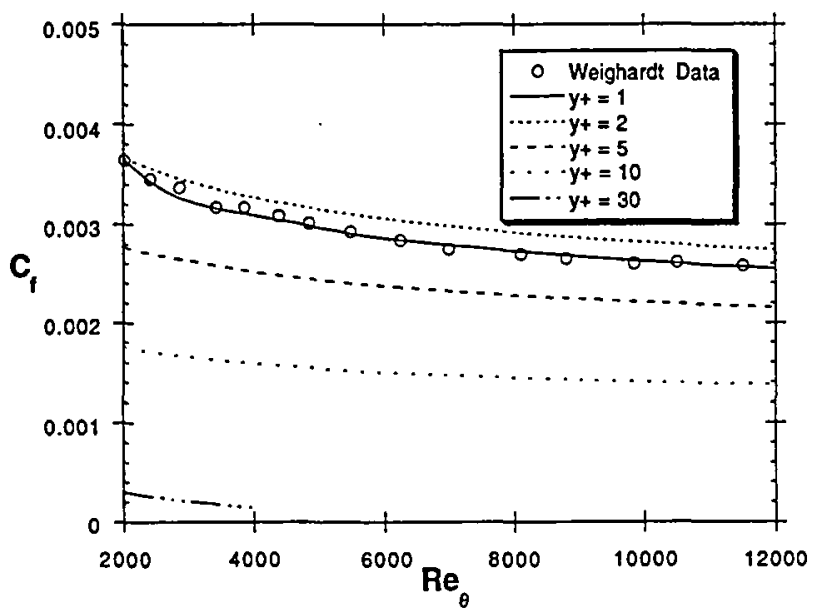

Fig. 9. Skin friction comparison for Baldwin-Lomax solutions.

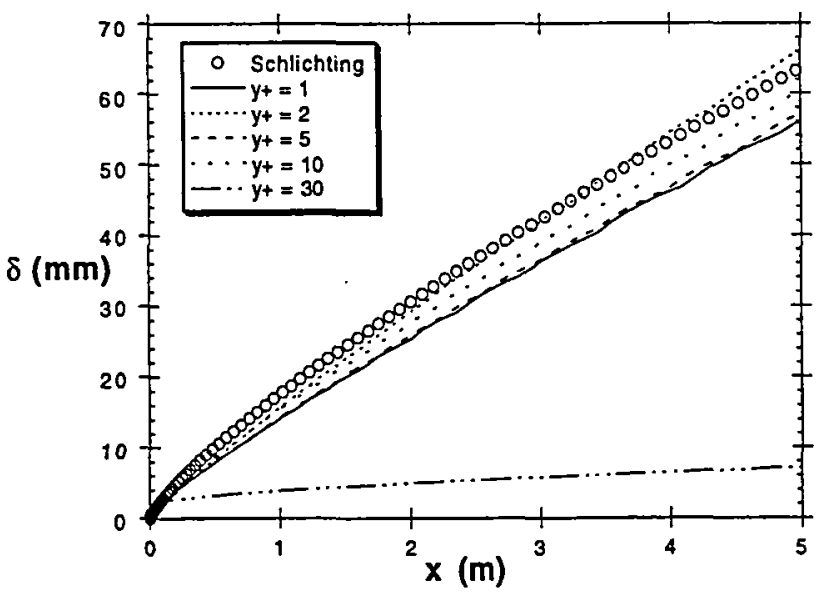

(a) Boundary layer thickness.

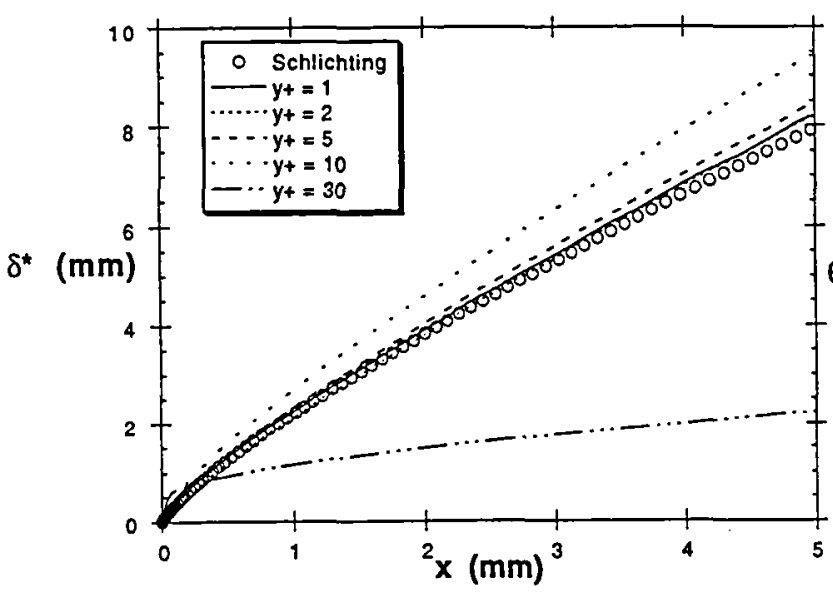

(b) Displacement thickness.

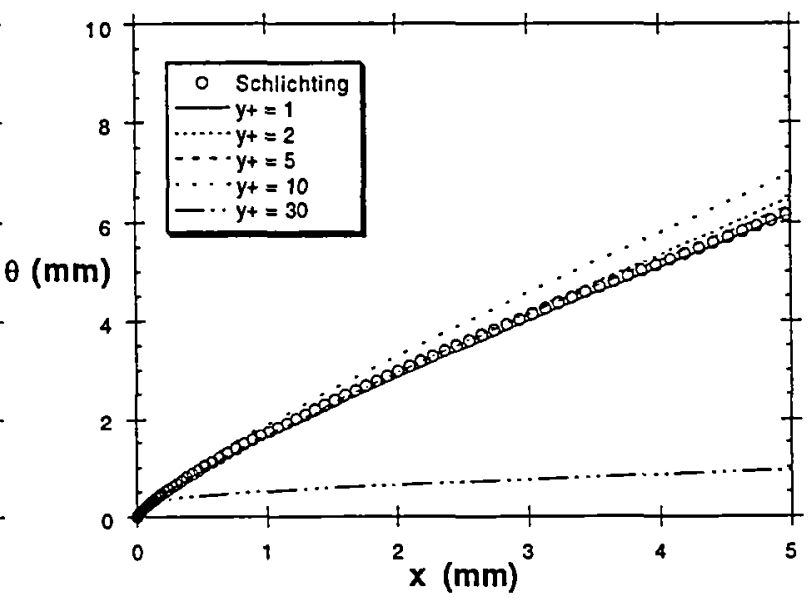

(c) Momentum thickness.

Fig. 10. Boundary layer quantities for the Baldwin-Lomax solutions. 


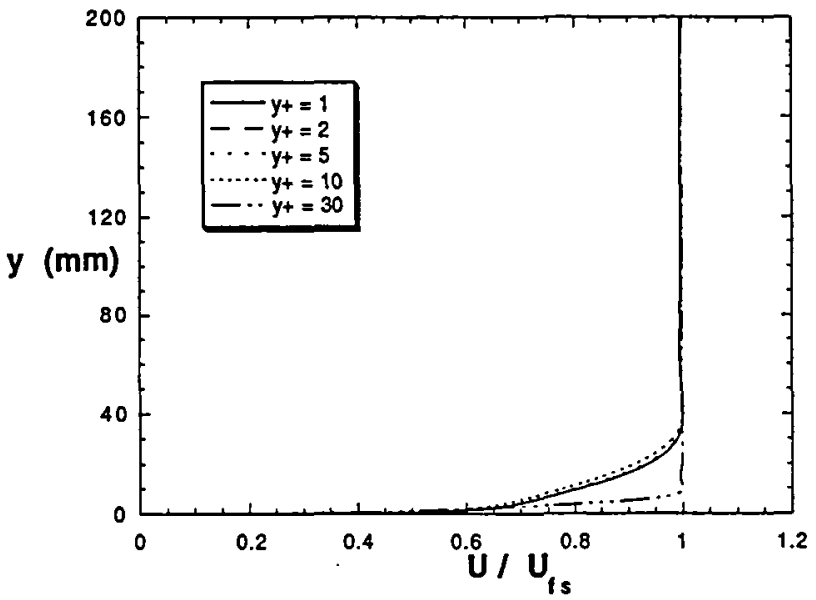

Fig. 11. Velocity profiles at $\mathrm{Re}_{\mathrm{x}}=\mathbf{1 0 , 0 0 0 , 0 0 0}$ for Baldwin-Lomax solutions.

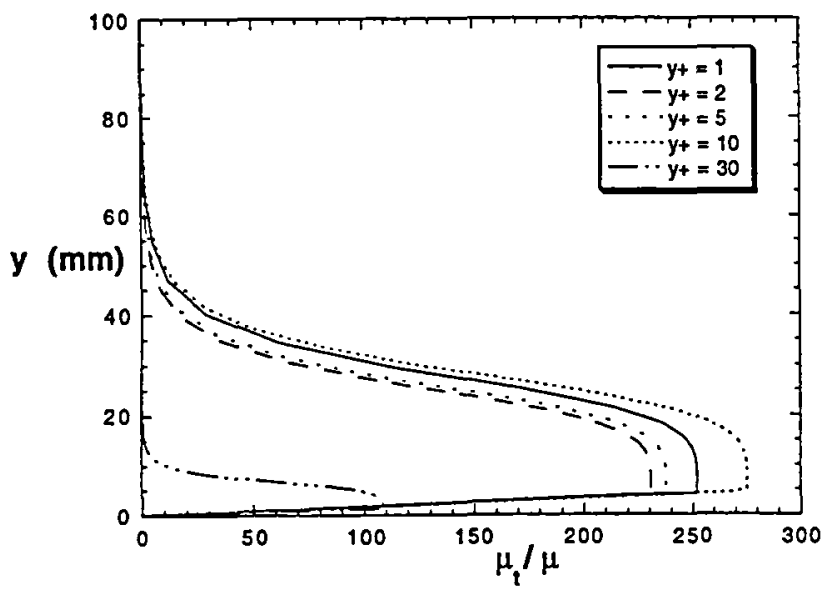

Fig. 12. Turbulent viscosity comparison for Baldwin-Lomax solutions.

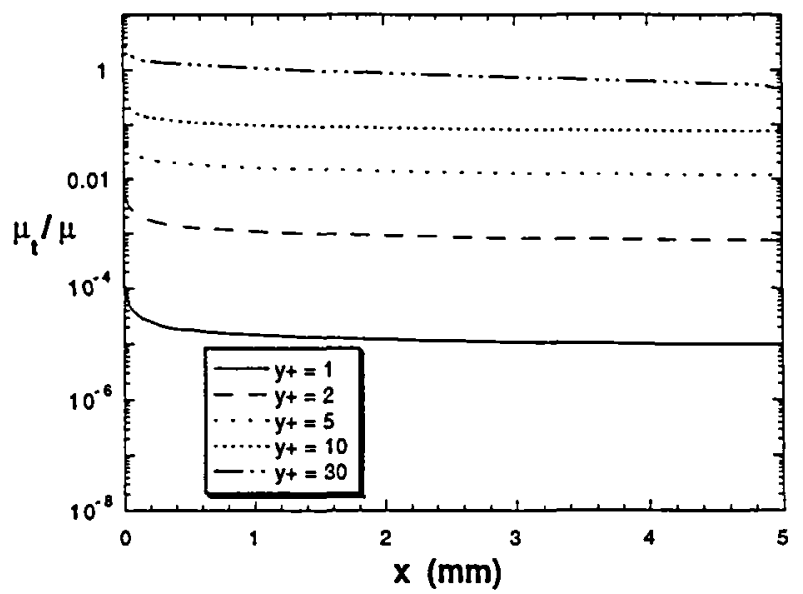

Fig. 13. Turbulent viscosity at the first point off the wall for Baldwin-Lomax solutions.

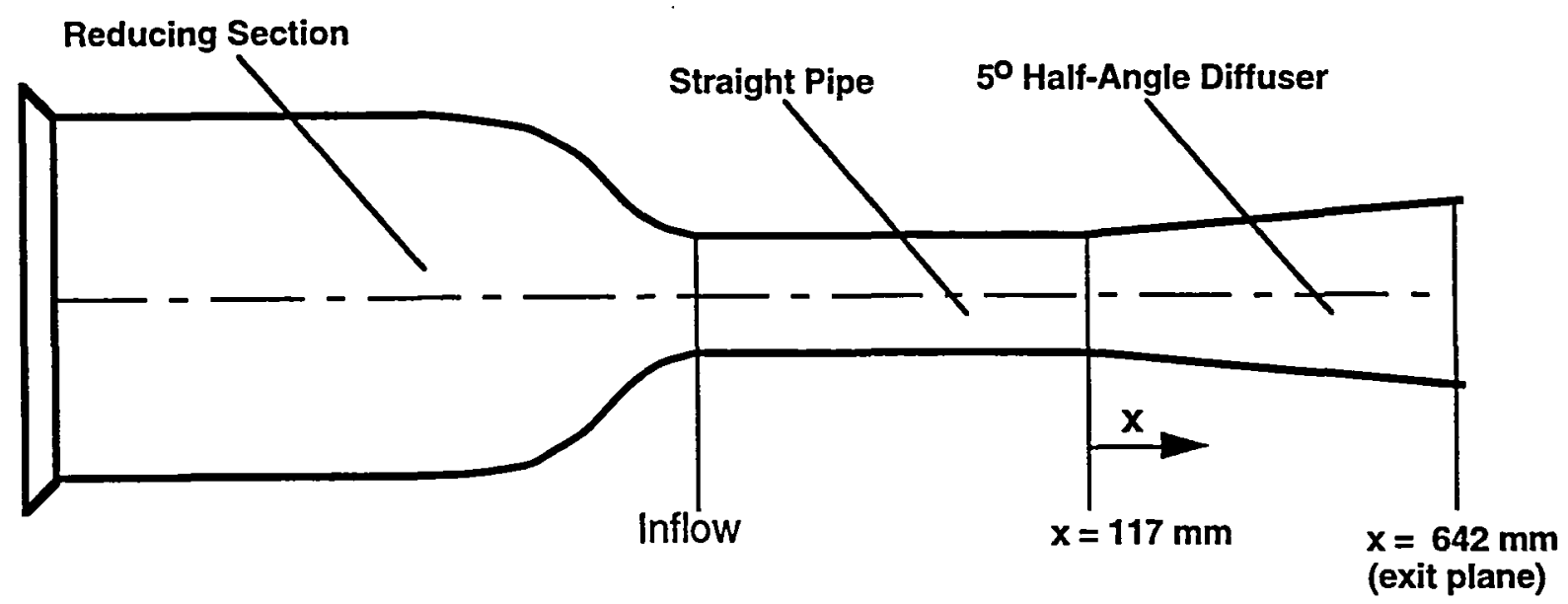

Fig. 14. Schematic of axisymmetric diffuser. 


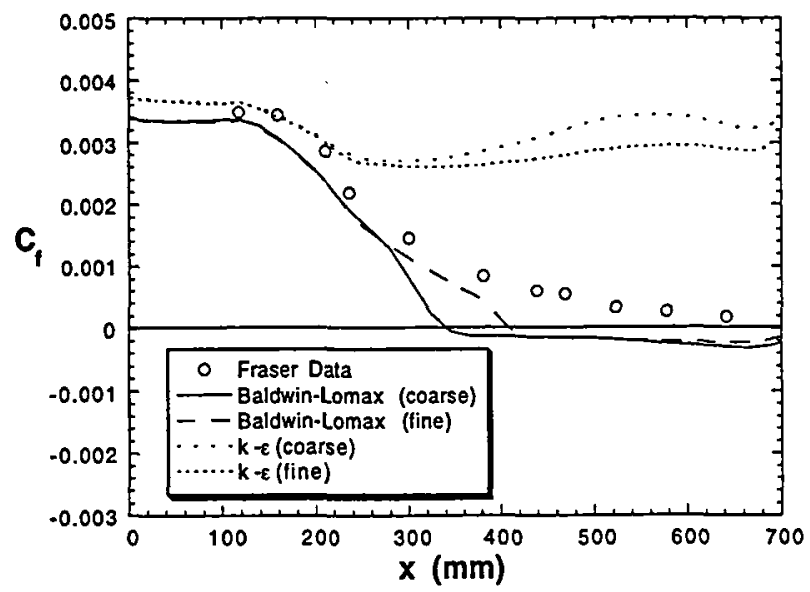

Fig. 15. Skin friction coefficient comparison for the diffuser flow.

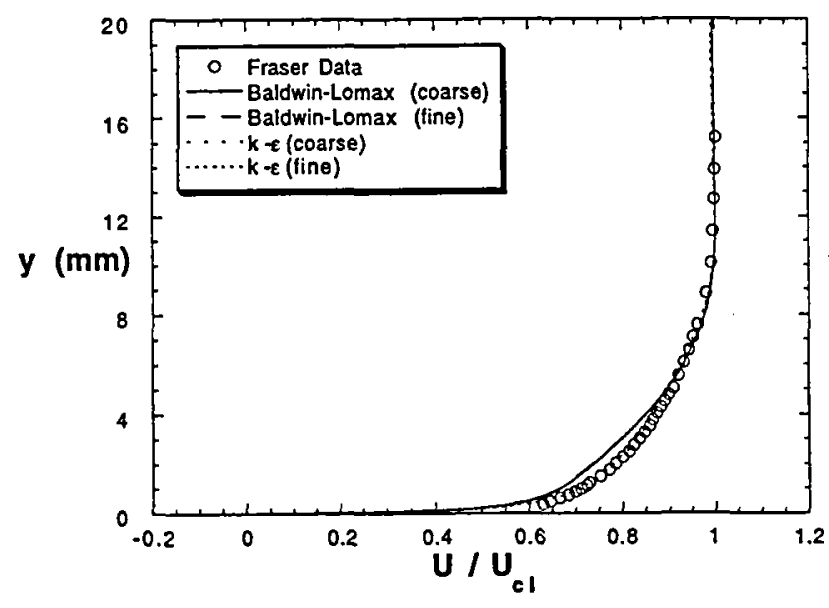

(a) $x=117 \mathrm{~mm}$.

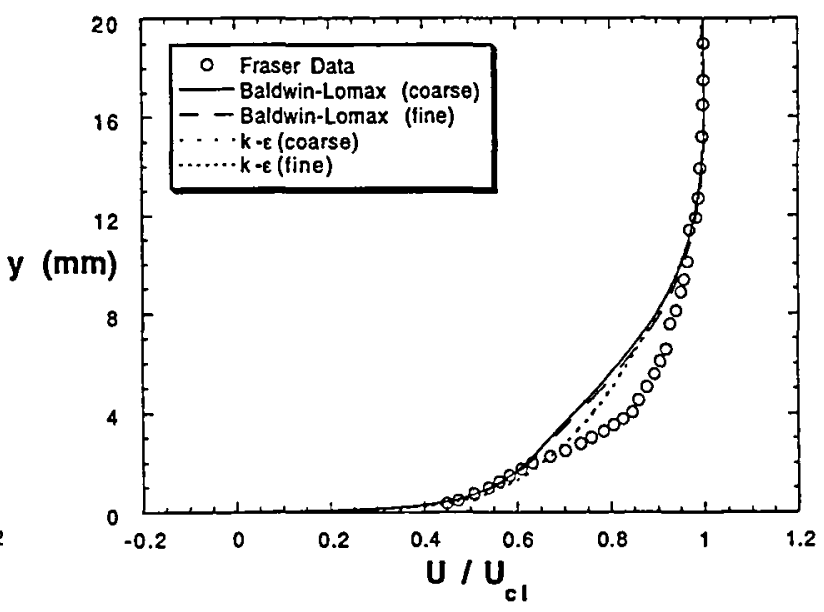

(b) $x=236 \mathrm{~mm}$.

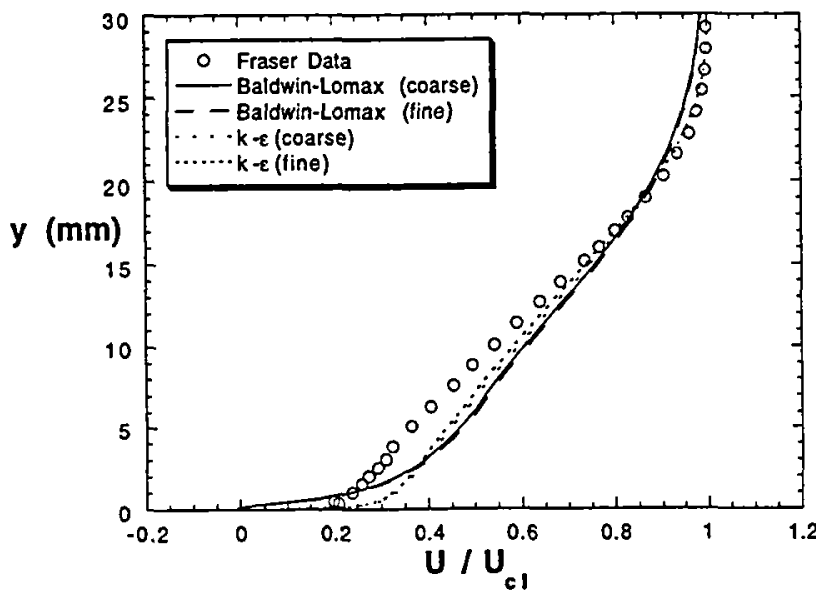

(c) $x=438 \mathrm{~mm}$.

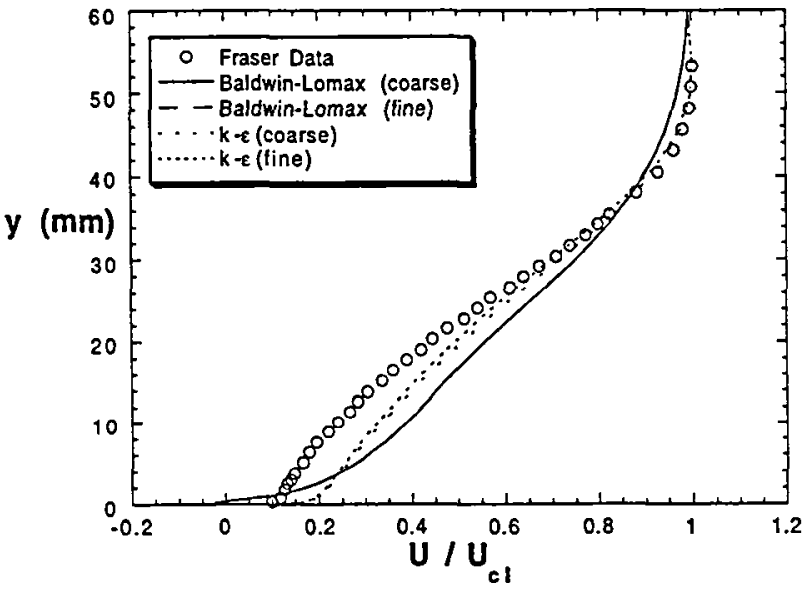

(d) $x=642 \mathrm{~mm}$.

Fig. 16. Velocity profiles for the axisymmetric diffuser flow. 


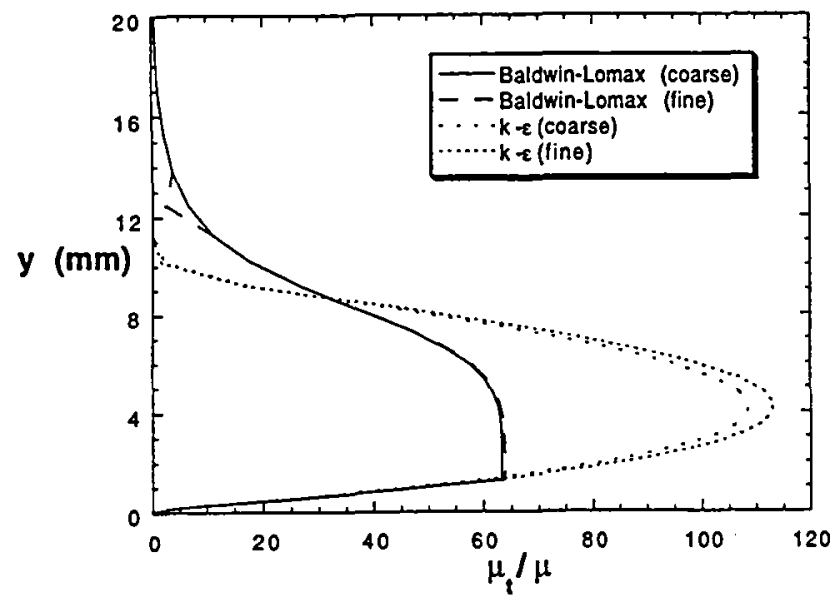

(a) $x=117 \mathrm{~mm}$.

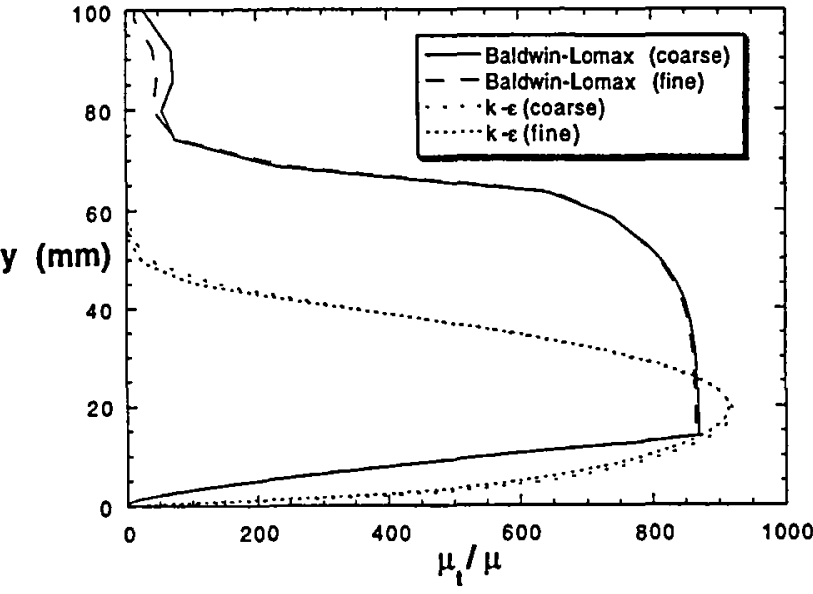

(b) $x=642 \mathrm{~mm}$.

Fig. 17. Turbulent viscosity comparison for the axisymmetric diffuser flow.

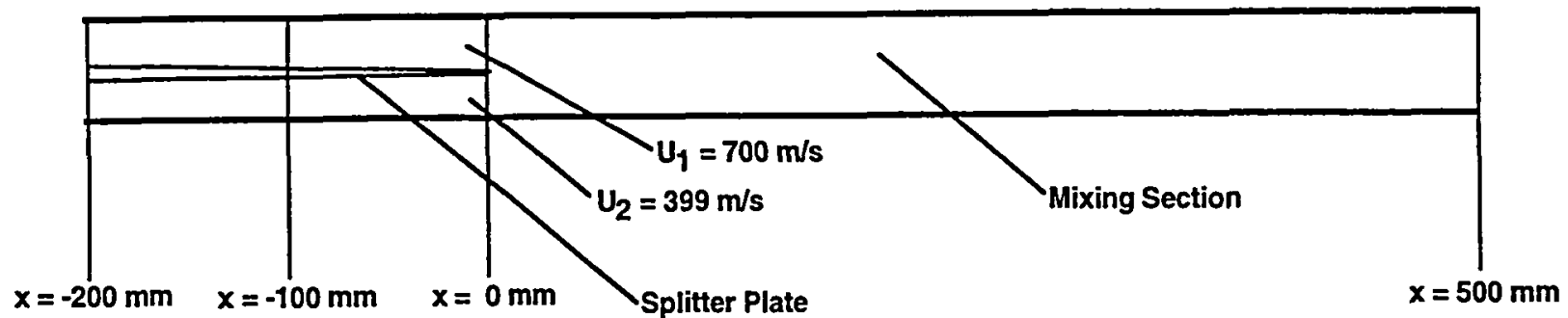

Fig. 18. Schematic of the planar mixing layer test case.

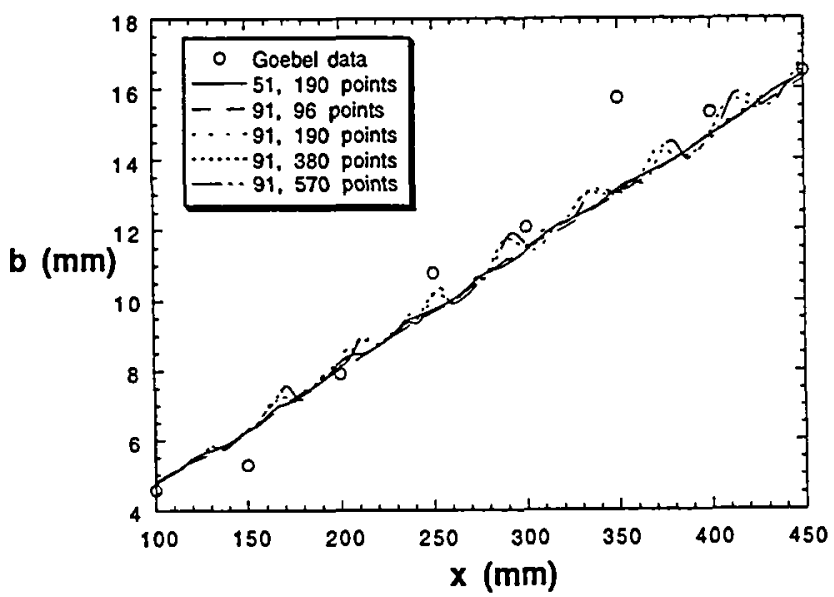

Fig. 19. Mixing layer growth for axial grid variations. 


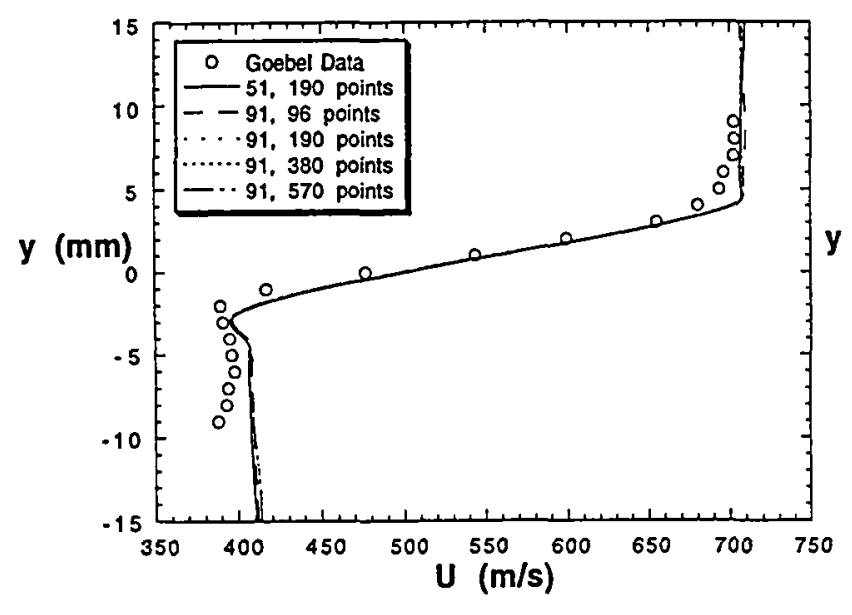

(a) $x=100 \mathrm{~mm}$.

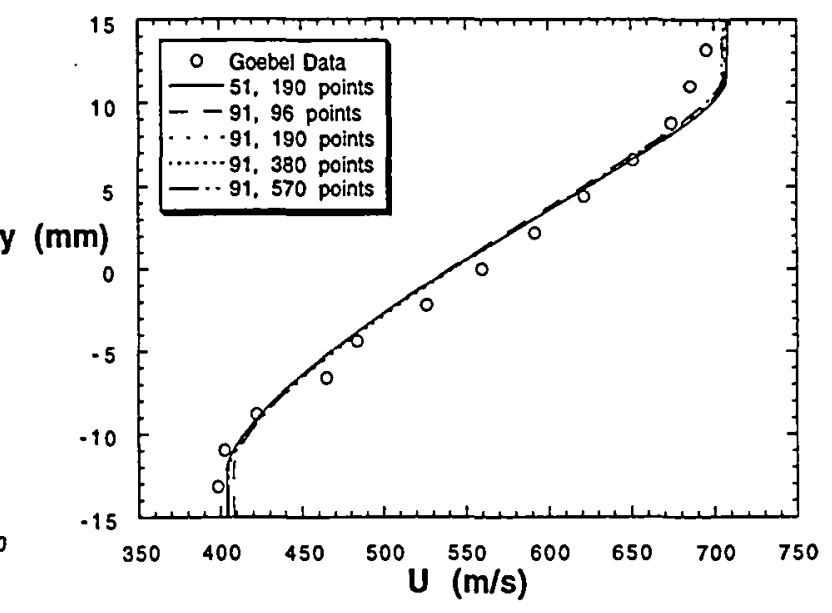

(b) $x=450 \mathrm{~mm}$.

Fig. 20. Velocity profiles for axial grid variations, mixing layer test case.

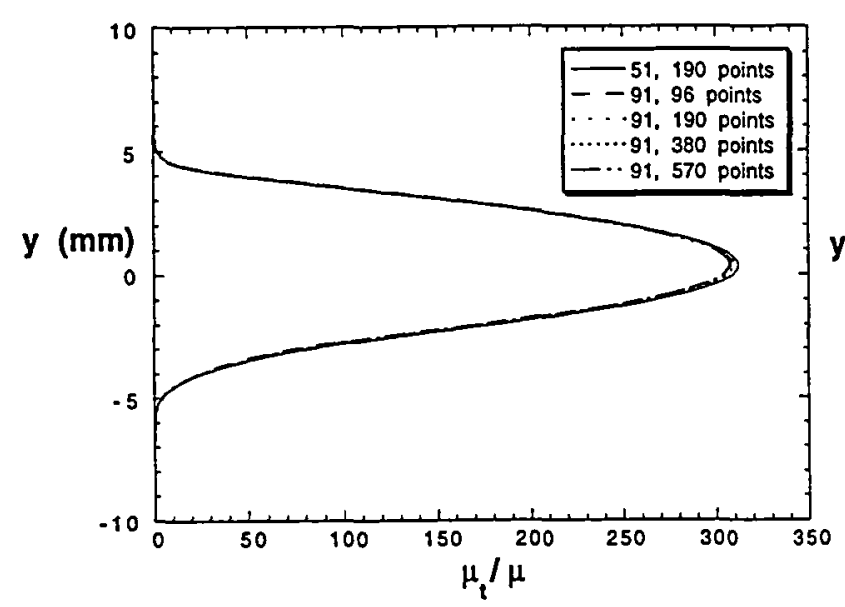

(a) $x=100 \mathrm{~mm}$.

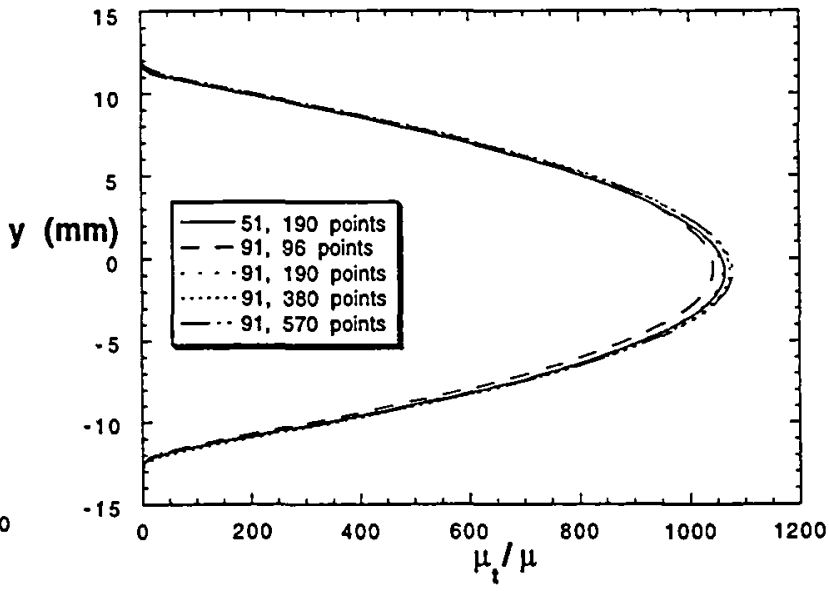

(b) $x=450 \mathrm{~mm}$.

Fig. 21. Turbulent viscosity profiles for axial grid variations, mixing layer test case.

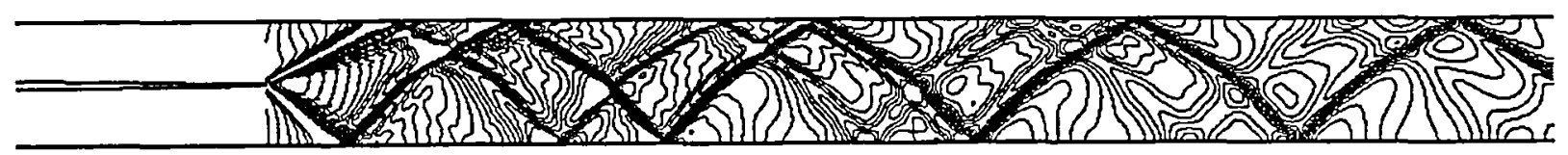

Fig. 22. Static pressure contours using 570 grid points in the mixing region. 


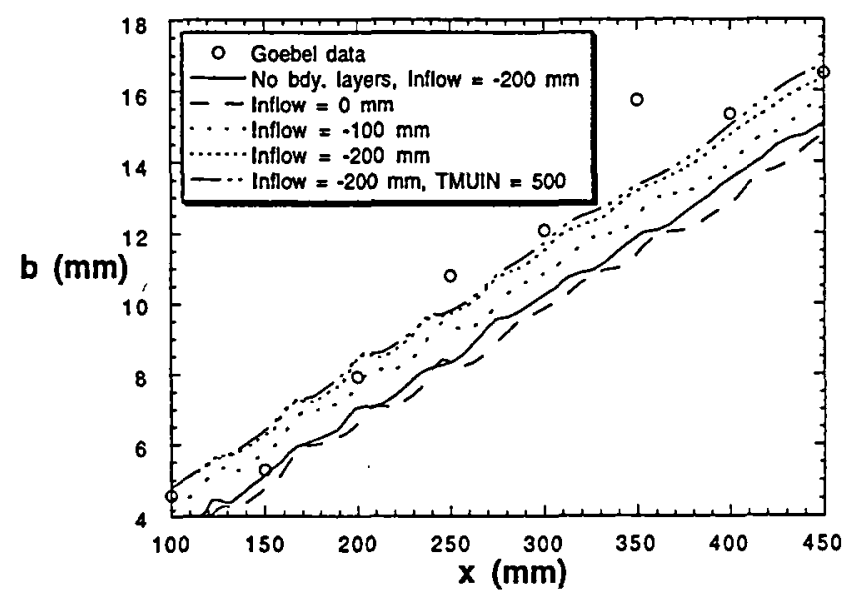

Fig. 23. Mixing layer growth for inflow boundary condition variations, mixing layer test case.

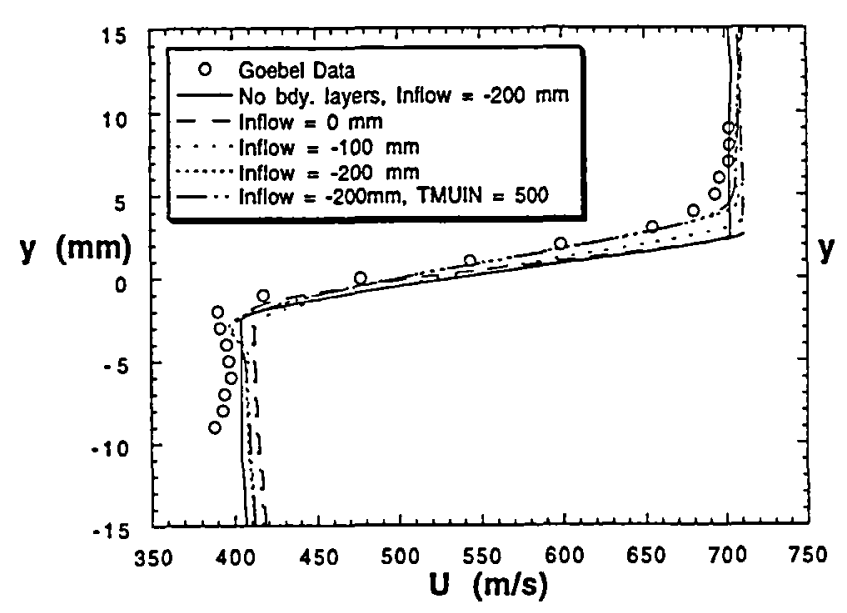

(a) $x=100 \mathrm{~mm}$.

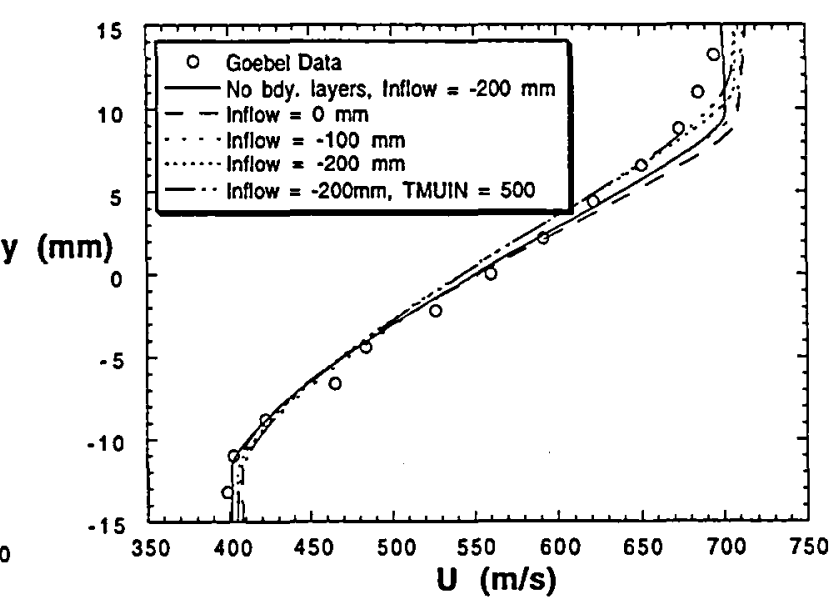

(b) $x=450 \mathrm{~mm}$.

Fig. 24. Velocity profiles for inflow boundary condition variations, mixing layer test case.

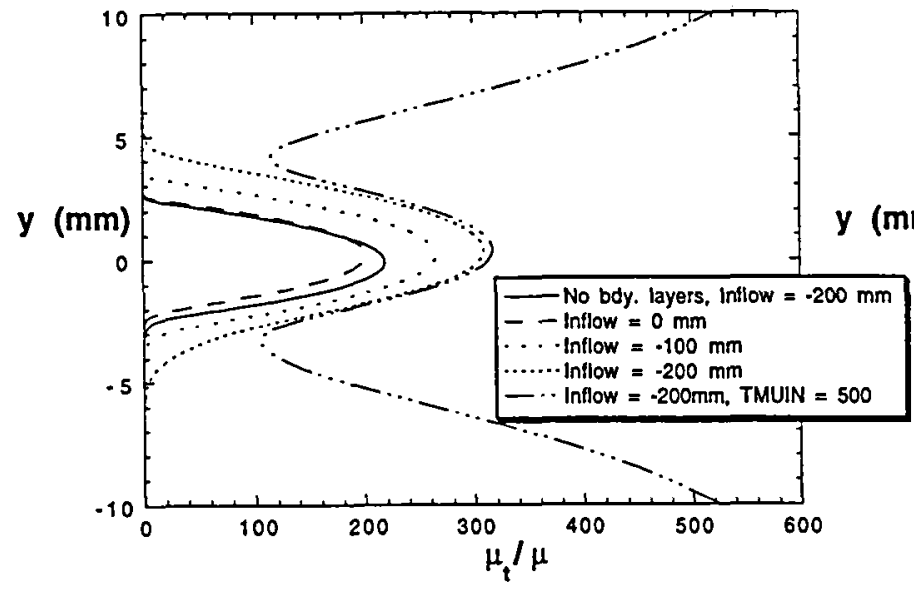

(a) $x=100 \mathrm{~mm}$.

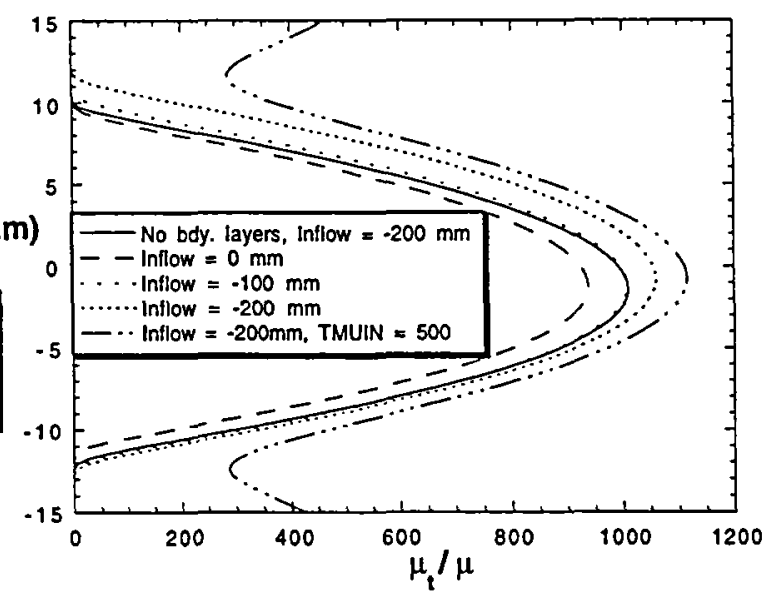

(b) $x=450 \mathrm{~mm}$.

Fig. 25. Turbulent viscosity profiles for inflow boundary condition variations, mixing layer test case. 
Public reponting burden for this collection of information is estimated to average 1 hour per response, including the time for reviewing instructions, searching existing data sources, gathering and maintaining the data needed. and completing and reviowing the collectlon of information. Send comments regarding this burden estimate of any other aspect of this collection of information, including suggestions for reducing this burden, to Washington Headquarters Services, Directorate for Iniormallon Operalions and Reports, 1215 Jellerson Davis Highway, Suite 1204, Arlington, VA 22202-4302, and to the Offico of Management and Budget, Papenwork Reduction Project (0704-0188), Washington, DC 20503.

\begin{tabular}{l|l|l|} 
1. AGENCY USE ONLY (Leave blank) & 2. REPORT DATE & 3. REPORT TYPE AND DATES COVERED
\end{tabular}

\section{\begin{tabular}{|r|r|}
\hline & July 1995 \\
\hline
\end{tabular}}

4. TITLE AND SUBTIILE

Grid Resolution and Turbulent Inflow Boundary Condition Recommendations for NPARC Calculations

6. AUTHOR(S)

Nicholas J. Georgiadis, Julianne C. Dudek and Thomas P. Tiemey
Technical Memorandum

5. FUNDING NUMBERS

WU-537-02-23

7. PERFORMING ORGANIATION NAME(S) AND ADDRESS(ES)

National Aeronautics and Space Administration

Lewis Research Center

Cleveland, Ohio 44135-3191
8. PERFORMING ORGANIZATION REPORT NUMBER

E-9711

10. SPONSORING/MONITORING AGENCY REPORT NUMBER

NASA TM-106959

AIAA-95-2613

Washington, D.C. $20546-0001$

11. SUPPLEMENTARY NOTES

Prepared for the 31st Joint Propulsion Conference and Exhibit cosponsored by AIAA, ASME, SAE, and ASEE, San Diego, Califomia, July 10-12, 1995. Nicholas J. Georgiadis and Julianne C. Dudek, NASA Lewis Research Center, Thomas P. Tierney, Massachusetts

Institute of Technology, Cambridge, Massachusetts. Responsible person, Nicholas J. Georgiadis, organization code 2740, (216) 433-3958.

12a. DISTRIBUTIONAVAILABILITY STATEMENT 12b. DISTRIBUTION CODE

Unclassified-Unlimited

Subject Category 02

This publication is available from the NASA Center for Aerospace Information, (301) 621-0390.

13. ABSTRACT (Maximum 200 words)

The effects of grid resolution and specification of turbulent inflow boundary conditions were examined using the NPARC code with the Baldwin-Lomax and Chien $\mathrm{k}-\varepsilon$ turbulence models. Three benchmark turbulent test cases were calculated: two were wall bounded flows and the third was a compressible mixing layer. The wall bounded flows were essentially insensitive to axial grid density; however, the location of the first point off the wall had a substantial effect on flow solutions. It was determined that the first point off the wall must be in the laminar sublayer $(y+\leq 5)$ for the entire boundary layer. For the compressible mixing layer case, the axial grid density affected the capturing of oblique shock waves in the mixing region, but the overall mixing rate was not strongly dependent on grid resolution. In specifying the inflow turbulent boundary conditions, it was very important to match the boundary layer and momentum thicknesses of the two flows entering the mixing region; calculations obtained with smaller or no boundary layers resulted in substantially reduced mixing. The solutions were relatively insensitive to freestream turbulence level.

\begin{tabular}{l}
\hline $\begin{array}{l}\text { 14. SUBJECT TERMS } \\
\text { NPARC; Turbulence; Grid resolution; Turbulent boundary } \\
\text { Shear layer; Mixing }\end{array}$ \\
$\begin{array}{l}\text { 17. SECURTY CLASSIFICATION } \\
\text { OF REPORT } \\
\text { Unclassified }\end{array}$ \\
$\begin{array}{c}\text { 18. SECURITY CLASSIFICATION } \\
\text { OF THIS PAGE } \\
\text { Unclassified }\end{array}$ \\
\hline
\end{tabular}

NSN 7540-01-280-5500
15. NUMBER OF PAGES

16

16. PRICE CODE

$\mathrm{A} 03$

20. LIMTAATION OF ABSTRACT

SECURITY CLASSIFICATION

Unclassified 
National Aeronautics and

Space Administration

Lewis Research Center

21000 Brookpark Rd.

Cleveland, $\mathrm{OH}$ 44135-3191

Officlal Business

Penalty for Private Use $\$ 300$

POSTMASTER: If Undeliverable - Do Not Return

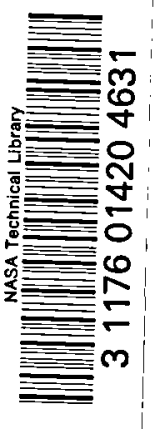

